\title{
Kinetic Studies of RNA Cleavage by Lanthanide(III) Macrocyclic Complexes
}

\author{
John P. Richard, ${ }^{*}$ Janct R. Morrow, AnnMaric C. O'Donoghue, and Sang Yong Pyun ${ }^{\text {t., }}$ \\ Department of Chemistr, Uninersity at Buffalo, SUNY, Buffalo, New York 14260-3000. USA \\ ${ }^{\dagger}$ Department of Chemistrv. Pukyong Nationat Liniversity, Busan 608-737, Korea \\ Received November 14.2003
}

Key Words : RNA cleavage, Lanthanide(III) macrocyclic complexes

There has been much eflort directed in recent years towards the design of catalysts for the cleavage of RN $\wedge_{1}{ }^{1-4}$ and the development of an underslanding of the mechanism for the cleavage reaction. ${ }^{5-7}$ There has been significant progress in both areas. Jowever, the rate aceclerations reported to date for synthetic catalysts of RN $\Lambda$ cleavage are, in general, far below those obtained for enzyme catalysts; and, there are a number of important unresolved questions about the mechanisms; the spontaneous and buller-catalyzed cleavage reactions which have been set out with great clarity in a previous review. ${ }^{j}$

Studies on the design of eatalysts of RNA cleavage are driven by signilicant advances in our understanding of catalyst mechanism; and investigations of novel catalysts with high activity oller the potential to improve our understanding of mechanism. Therefore, a possibility exists for the synergy of results from collaboralive work on the mechanism of RNA cleavage and the design of catalysts of the cleavage reaction. There are dilliculties in merging studies on mechanism and design, because the strengths and interests required to make progress in these dillerent types of sludies are nol often found in a single laboratory. Studies on reaction mechanism are driven primarily by intellectual curiosity and require a detailed understanding of kineties and structure-reactivity effects. On the other hand, the catalyst design is driven to a greater extent by the desire to produce reagents with practical applications and requires considerable experience in the synthesis of inorganic metal complexes and an understanding of their propertics.

In this work, we have investigated kinctics of uridylyl( $3^{1}$ $\left.\rightarrow 5^{\prime}\right)$ uridine $\left(3^{\prime}, 5^{\prime}-\mathrm{l} \mathrm{p} \mathrm{U}\right)$ cleavage by a lanthanide catalysts. Mononuclear complexes containing two types of macrocyclic ligands including complexes which contain $\mathrm{La}(S-$

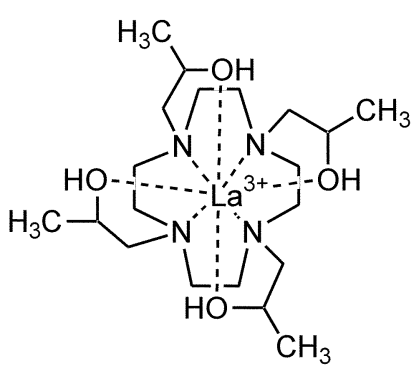

$$
\text { La(THP) })^{3+}
$$

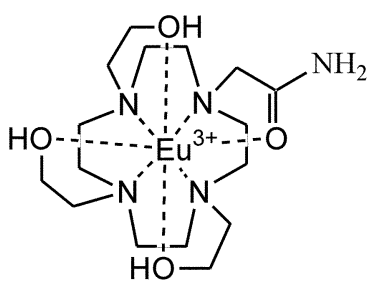

$\operatorname{Eu}(\mathrm{ATHC})^{3+}$
TIJP) $)^{3 \prime}$ and Eu( $\left.\Lambda T H C\right)^{3 /}$ have been sludied.

The long-range goal of this work is to obtain basic insight in to a challenging chentical problem, and to produce catalytic agents that are of practical value.

\section{Experimental Section}

General Procedure. All reagents were of reagent grade and were used without further purilication, unless otherwise noted. Milli-Q purified water was used for kinctic experiments. CIJES(2-(cyclohexylamino)ethanesulfonic acid) and uridylyl( $\left.3^{\prime} \rightarrow 5^{\prime}\right)$ uridine ammonium salt(3',5'-U $\mathrm{pU}(J)$ were of reagent grade and purchased from Sigma Chemicals and Aldrich. The free base form of cyclen(1,4.7.10-ctraazacyclododecane) was generated by passing the telrahydrochloride salt (parish chemical) through a Dowex $1 \times 8-200$ anion exchange column $(30 \mathrm{~cm} \times 2.5 \mathrm{~cm}$. hydroxide form). Solution $\mathrm{pl}$ I values were measured at $25^{\circ} \mathrm{C}$ by use of an Orion digital pH I meter equipped with a temperature compensation probe.

$\mathrm{La}\left(\mathrm{CF}_{3} \mathrm{SO}_{3}\right)_{3}$ and $\mathrm{Eu}\left(\mathrm{CF}_{3} \mathrm{SO}_{3}\right)_{2}$ were obtained by treating the respective lanthanide oxides with concentrated trilluoromethanesulfonic acid as reported previously. 1,4,7,10Tetrakis(2-hydroxypropyl)-1,4,7,10-tetrazacyclododecanc (S-T]IP) was prepared by treating cyclen with a $50 \%$ excess of propylene oxide in absolute ethanol at room temperature for 2 days as reported previously. 1 -(Carbamoylmethyl)4,7,10-tris (2-hydroxyethyl)-1,4,7,10-tetraazacyclododecane ( $\Lambda$ TIIC) was prepared through four step reactions which started from the reaction of cyclen with benzyl chloride by the well-known method. ${ }^{10}$ The lanthanide complexes $\mathrm{La}(S-$ $\mathrm{Tl} \mathrm{P})\left(\mathrm{CF}_{3} \mathrm{SO}_{3}\right)_{3}$ and $\mathrm{Eu}(\Lambda \mathrm{TH} \mathrm{IC})\left(\mathrm{CF}_{3} \mathrm{SO}_{3}\right)_{3}$ were prepared from their respective lanthanide salts and the frec base form of the macrocycle as described previously. ${ }^{10.11}$

Kinetic Measurements. The kinetics for cleavage of 3',5'UplJ were measured by monitoring the appearance of uridine by use of a Waters 600E I IPLC equipped with a 490 UV-vis detector. The $p$-nitrobenzenesullonate sodium salt was used as an internal standard. Reactions were analyzed on a C.18 column $(250 \mathrm{~mm} \times 4.6 \mathrm{~mm})$. Solvent $\Lambda$ : $60 \mathrm{mM}$ acctate buller at $\mathrm{pH}$ 4.3. Solvent B: $100 \%$ McOH. For experiments with $3^{\prime}, 5^{\prime}-\mathrm{UpU}$, an isocratic flow of $90 \%$ solvent $\Lambda$ and $10 \%$ solvent $B$ was used with an isocratic llow of $2.0 \mathrm{~mL} / \mathrm{min}$ over $20 \mathrm{~min}$. The reaction mixture (total volume $0.5 \mathrm{~mL}$ ) contained $0.32 \mathrm{mM}$ of 3'.5'- $\mathrm{UpU}, 0-1.5 \mathrm{mM}$ of lanthanide complexes, $20 \mathrm{mM}$ CIIES buffer (pIl 8.9), 
$0.02 \mathrm{mM}$ internal standard, and $0.1 \mathrm{M} \mathrm{NaNO}_{3}$. A $50 \mu \mathrm{l}$. aliquot was removed from the reaction mixture, then $50 \mu \mathrm{l}$. of $0.1 \mathrm{M}$ acetate buffer was quenched and subjected to $\mathrm{HPI} . \mathrm{C}$ analysis to determined the $\mathrm{t}=0$ integration. Because the slow rate of cleavage of $3^{\prime}, 5^{\prime}-\mathrm{UpU}$, the method of initial rates was employed.

\section{Results and Discussion}

Kinetics of Cleavage of $3^{\prime}, 5^{\prime}-\mathrm{U}_{\mathrm{p} U}$. The kinetics of cleavage of $3^{\prime}, 5^{\prime}-\mathrm{U}$ pU by the lanthanide(III) complexes was monitored by the production of uridine species by use of $\mathrm{HPI}$.C equipped with a $490 \mathrm{\Gamma}$ : UV-vis detector.

The products of cleavage of $3^{1}, 5^{\prime}-\mathrm{UpU}$ were seperated by $\mathrm{HPIC}$ and identified with peak detection at $240 \mathrm{~nm}$ using a Waters 996 diode array detector. The products were identified by comparison of the HPI.C retention time with that for authentic material. The products were generally analyzed after a reaction time of $20 \mathrm{~min}$. Cleavage of $3^{1} .5^{\prime}-$ UpU produces $2^{\prime}, 3^{\prime}$-cyclic phosphate $(3.27 \mathrm{~min})$, U3'-P (3.8 min), U2'-P (4.5 min), Uridine (5.5 min), 2'.5'-UpU (16.7 $\mathrm{min})$, and 3 ',5'-UpU (17.7 min).

The $f_{\text {ckatate }}$ was calculated from the ratios of the peaks areas of the uridine and 31,5 -UpU determined by HPI.C analysis, according to eq. (1). $f_{\text {clum }}$ is the fraction of $3^{\prime}, 5^{\prime}-$ $\mathrm{UpU}$ that is converted to the uridine product.

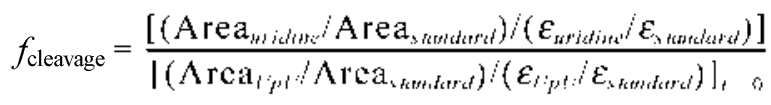

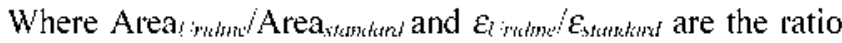
of peak areas from HPLC analysis and the extinction coefticients of uridine and internal standard at $240 \mathrm{~nm}$. The ratio of the extinction coefficients for the uridine and standard

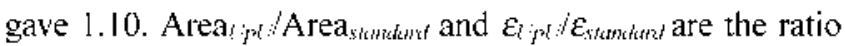
of peak areas from HPLC analysis and the extinction coefficients of 3',5'-UpU and internal standard at the wavelength of the analysis. The ratio of extinction coeflicients for

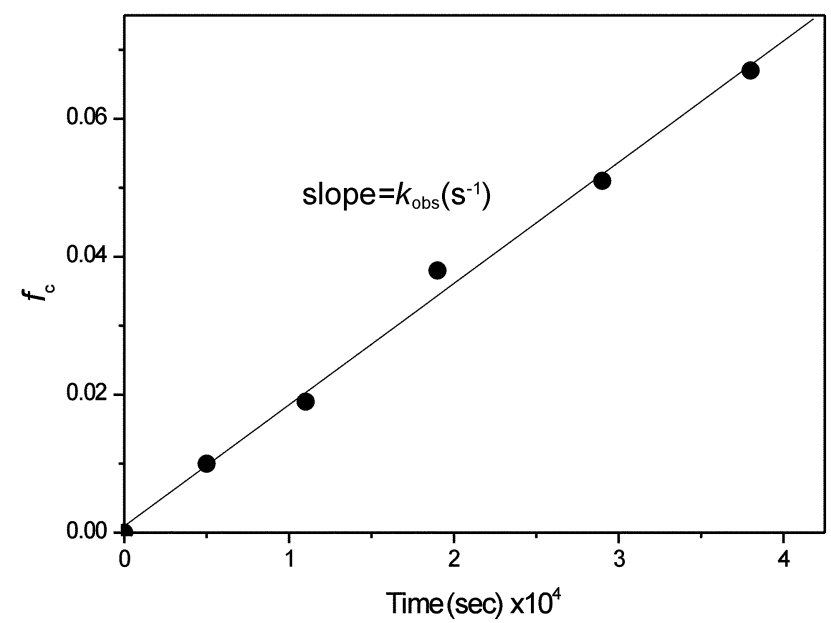

Figure 1 . Plot of $f_{\text {clavase }} w$. time for the catalytic cleavage of $3^{4} .5^{\prime}$ U.pl at $25^{\circ} \mathrm{C}$.
Table I. The observed rate constants for the catalysis of cleavage of $3^{\prime} .5^{\prime}-\mathrm{U} \mathrm{pl}$ by $\mathrm{La}(S-\mathrm{TH})^{3}$ and $\left(\mathrm{Eu}-\mathrm{ATH} \mathrm{CC}^{3}\right.$ complexes at $25^{\circ} \mathrm{C}$ and $\mathrm{pH} 8.9^{\prime \prime}$

\begin{tabular}{|c|c|c|}
\hline \multirow{2}{*}{ [Complex]. mM } & \multicolumn{2}{|c|}{$10^{8} k_{\text {ots }}\left(s^{1}\right)$} \\
\hline & La(S-THP) ${ }^{3}$ & $\mathrm{Eu(ATHC})^{31}$ \\
\hline 0.5 & 20.7 & 2.55 \\
\hline 1.0 & 39.8 & 4.90 \\
\hline 1.5 & 54.3 & 5.95 \\
\hline
\end{tabular}

"Reactions were itr 20 m.M CHF.S bufter with 0.1 Q $\mathrm{NaNO}_{3}$

the these materials determined 2,14 . The rate constants $\left(k_{\text {cbss }}\right)$ for cleavage of $3^{1}, 5^{1}-\mathrm{UpU}$ were calculated from the slope of a plot of $f_{\mathrm{L}}$ aggainst time (Figure 1 ).

The rate constants for cleavages from $3^{1}, 5^{\prime}-\mathrm{UpU}$ promoted by $\mathrm{l}$ a $(S-T H P)^{3+}$ and $\mathrm{Cu}(\mathrm{ATHC})^{3+}$ complexes are listed in Table 1 . In the presense of a $\left[\right.$ a $(S-T H P)^{3-}$ complex $(0.5 \mathrm{mM}$, $1.0 \mathrm{mM}$, and $1.5 \mathrm{mM})$, the rate constants $\left(k_{0 \mathrm{~h}}\right)$ were $2.07 \times 10^{-7} \mathrm{~s}^{-1} .3 .98 \times 10^{-7} \mathrm{~s}^{-1}$, and $5.43 \times 10^{-7} \mathrm{~s}^{-1}$, respectively. For $\mathrm{Tu}(\mathrm{ATHC})^{3-}$ complex $(0.5 \mathrm{mM}, 1.0 \mathrm{mM}$, and $1.5 \mathrm{mM})$, the rate constants $\left(k_{\text {ctoss }}\right)$ were $2.5 \times 10^{-8} \mathrm{~s}^{-1}, 4.90 \times 10^{-8} \mathrm{~s}^{-1}$. and $5.95 \times 10^{-8} \mathrm{~s}^{-1}$, respectively.

Plots for the lanthanide(II) comlexes promoted cleavages from 3', '-UpU against complex concentration are straight lines with positive intercepts (Figure 2). This indicates that the rate equation can be expressed as $k_{\text {cols }}=k_{\mathrm{c}}[$ complex $]+k_{0}$. In this equation, the first term is the second-order rate constants by metal complex-catalyzed $\left(k_{i}\right)$ and the second term is the first-order rate constant for the spontaneous reaction. The $k_{\mathrm{i}}$ values were determined from the slopes of the plots (Figure 2). The $k_{0}$ value was obtained by the same procedure except that the reaction was not added to complex to reaction solution.

The second-order rate constants for cleavages from 3',5'UpU promoted by lantlanide(III) complexes are listed in Table 2. The second-order rate constants of cleavages of $3^{\prime}, 5^{\prime}-\mathrm{UpU}$ by $\mathrm{la}(\mathrm{S}-\mathrm{THP})^{3+}$ and $\mathrm{\Gamma u}(\mathrm{ATHC})^{3+}$ in solutions buffered at $\mathrm{pH} 8.9$ were measured to be $3.36 \times 10^{-4} \mathrm{M}^{-1} \mathrm{~s}^{-1}$

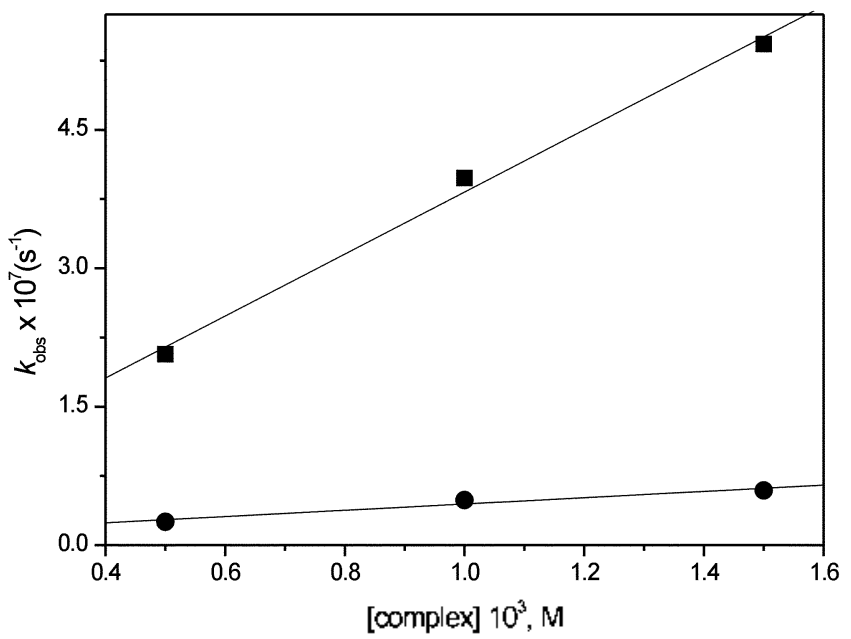

Figure 2. Plots of [complex] vs. $k_{\text {vl }}$ for the cataly sis of cleavage of

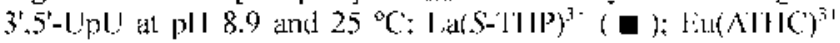
(๑). 
Table 2. Kinetic data for the cleavage of $3^{\prime}, 5^{\prime}-\mathrm{L}$, pl I by Lanthanide complexes at $\mathrm{pH} 8.9$ and $25^{\circ} \mathrm{C}$.

\begin{tabular}{|c|c|c|c|}
\hline [Complex]. M & $k_{c}\left(\mathrm{M}^{-1} \mathrm{~s}^{-1}\right)$ & $k_{0 .} s^{-1}$ & $k_{1} / k_{0} . \mathrm{M}^{-1}$ \\
\hline I.a(S-IIII) $)^{3-}$ & $3.36 \times 10^{-4}$ & $1.6 \times 10^{-8}$ & $2.1 \times 10^{4}$ \\
\hline Fu(AllIC $)^{3-}$ & $3.40 \times 10^{-5}$ & $1.6 \times 10^{-8}$ & $2.1 \times 10^{3}$ \\
\hline
\end{tabular}

and $3.40 \times 10^{-5} \mathrm{M}^{-1} \mathrm{~s}^{-1}$, respectively. The first-order rate constant for the cleavage of $3^{\prime}, 5^{\prime}-\mathrm{UpU}$ in the absense of metal complex was measured to be $1.6 \times 10^{-8} \mathrm{~s}^{-1}$. The $k_{\mathrm{s}} / k_{0}$ values indicating catalytic ability of metal complexes are larger for $\mathrm{La}\left(S-\mathrm{T}^{-} \mathrm{H}^{3}\right)^{3+}$ complex than those for $\mathrm{Eu}(\mathrm{ATCHC})^{3+}$ coimplex.

Mechanism for Cleavage of RNA. The 2'-OH of the ribose ring greatly increases the lability of RNA compared to DNA., ${ }^{12}$ and provides an additional site for catalysis of RNA cleavage. This is because RNA cleavage proceeds with intramolecular attack of $2^{\prime}-\mathrm{OH}$ on the phosphate diester to form a cyclic 2,3-phosphate diester (Scheme 1) ${ }^{3,5,1.3}$

There are three sites at phosphate diesters where interactions with a metal ion complex might result in stabilization of the transition state for the cleavage of model ribonucleic acid phosphate diesters $\mathbf{1 - O R}$. (i) The metal ion may form a chelate to the anionic phosphate group (a, 1-OR). The effect of this interaction is to increase the electrophilic reactivity of the phosphate group by stabilizing the transition state for formation of the oxyphosphorane dianion. (ii) The metal ion may interact with the $C-2$ oxygen $(b, 1-O R)$ and facilitate formation of a nuclelphilic alkoxide ion. (iii) The metal ion may interact with the oxygen of the leaving group (c, 1-OR) and stabilize the negative charge that developes at the transition state for explusion of this leaving group.

Evalution of Catalytic Activity of Macrocyclic Complexes. Lanthanide complexes of 1,4,7,10-tetraazacyclododecane-1,4,7,10-tetraacetate (DOIA) are among the most thermodynamically stable and kinetically inert lanthanide (III) complexes known to date. ${ }^{\text {lit }}$ The tetraazacyclododecane derivatives reported here are an attractive choice as ligands because of their ease of functionalization for attachment to bimolecules ${ }^{15}$ and the large choice of pendent groups for modification of macrocycle properties. ${ }^{16}$

To ascertain the effect of a pendent groups on RNA cleavage rates, macrocyclic complexes of Eu(llI) with an amide and three hydroxyethyl pendent groups and the macrocyclic complexes of La(III) with a single stereoisomer that has the $S$ configuration at the $\alpha$-carbon of the hydroxypropyl groups have been studied.

Kinetic experiments with $\mathrm{La}\left(\mathrm{S}-\mathrm{THP}^{\mathrm{3}}\right)^{3-}$ and $\mathrm{Eu}(\mathrm{AIHC})^{3-}$ complexes demonstrate that these complexes promote for the cleavage of the $3^{1}, 5^{\prime}-\mathrm{UpU}$ (Tables $1,2 \&$ Figure 1 ). The second-order rate constants of cleavages of $3^{1}, 5^{\prime}-\mathrm{UpU}$ by $\mathrm{La}(\mathrm{S}-\mathrm{J} \mathrm{HP})^{3+}$ and $\mathrm{Eu}(\mathrm{AJHC})^{3-}$ in solutions buffered at $\mathrm{pH}$ 8.9 were measured to be $3.36 \times 10^{-4} \mathrm{M}^{-1} \mathrm{~s}^{-1}$ and $3.40 \times 10^{-5}$ $\mathrm{M}^{-1} \mathrm{~s}^{-1}$, respectively. The second-order rate constants for the $\mathrm{La}\left(\mathrm{S}-\mathrm{JHP}^{3}\right)^{3+}$ complex is approximately 10 fold larger than that obtained for $\mathrm{Eu}(\mathrm{AT} H \mathrm{HC})^{\text {i+ }}$ complex. The ability of rate accelerations for this reaction may also be deduced by comparing the $k_{v} / k_{0}$ values. A larger value of $k_{v} / k_{0}$ for catalysis of cleavage of RNA is expected for catalysis by metal ion complexes that specifically stabilize the transition state. $\mathrm{La}\left(S-\mathrm{JHP}^{3}\right)^{3-}$ and $\mathrm{Eu}(\mathrm{ATHC})^{3+}$ promote cleavage of $3^{\prime}, 5^{\prime}-\mathrm{UpU}$ approximately $10^{3}-10^{4}$ fold the larger than that in the absence of complexes under same conditions. Stabilization may result from interaction of the metal ion with the phosphate oxygen, the ribose $2^{\prime}-\mathrm{OH}$ or leaving group. The $\mathrm{La}\left(S-S^{-} \mathrm{HP}^{3}\right)^{3+}$ complex is also 10 -fold more effective than Eu(Al'HC) $)^{3+}$ complex. In conclusion, for cleavage of $3^{\prime}, 5^{\prime}-$ $\mathrm{UpU}$, the $\mathrm{La}\left(S-\mathrm{C}^{\prime} \mathrm{HI}^{3}\right)^{3+}$ complex is a better promoter than the Eu(AIHC) $)^{3+}$ complex.

The pendent groups will undoubtedly have an effect on the kinetic inertness of the lanthanide(III) complexes as well as its ability to catalyzed the cleavage of RNA. For cleavage of bis(4-nitrophenyl)phosphate, the substitution of one alcohol group of Eu([HED) $)^{--}$with an amide group does not substantially retard reactions where the pendent alcohol group is the nucleophile. ${ }^{17}$ In contrast, the hydrolytic cleavage of RNA by lanthanide(III) mycrocyclic complexes is much more sensitive to macrocycle structure. Eu(III) macrocyclic complexes with mixed amide and alcohol pendent groups are 10-100 fold less effective catalysts for phosphate diester transesterfication or RNA cleavage than Eu(THED) ${ }^{3-}$ (IHED $=1,4,4,7$-tetrakis(2-hydroxyethyl)-1,4,7,10-tetraazacyclododecane). ${ }^{17}$ A simple explanation for the enhanced reactivity of Eu(THED) $)^{3 \prime}$ containing only hydroxyethyl groups compared to macrocyclic complexes with mixed amide and hydroxyethyl is that the hydroxy group facilitates cooperative catalysis by the chelated lanthanide(III) ion. Hydroxy pendent groups are activated by metal ion coordination to
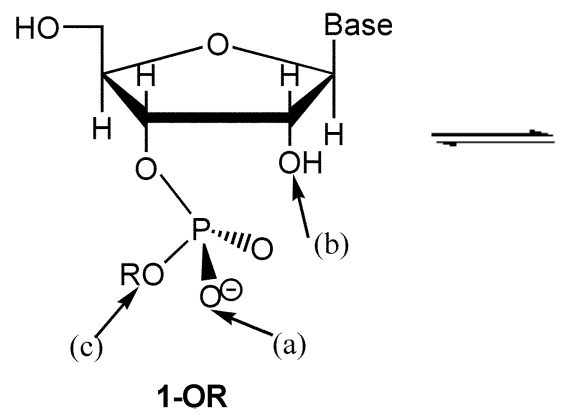

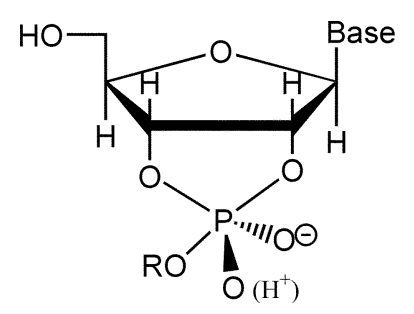

Oxyphosphorane intermediate

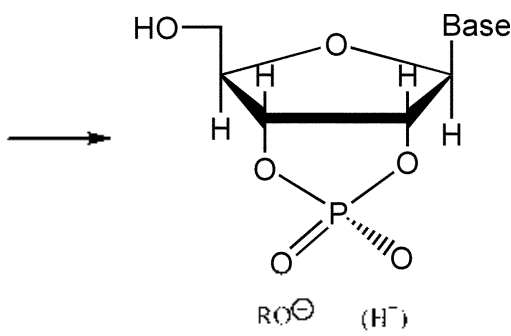

Cyclic 2', 3'-phosphate diester

Scheme 1. The mechanism for cleavage of phosphate diesters. 
become potent nucleophiles ${ }^{1 \varepsilon_{a}, 18 b}$ while amide groups impart kinetic inertia toward metal ion dissociation. ${ }^{18 \mathrm{c}, 1 \mathrm{~b}}$

Secondly. metal ion geonetry and metal ion coordination preferences are also important in cataly sis.

For relatively small metals ions such as $\mathrm{Cu}^{2+} \cdot \mathrm{Ni}^{\hat{2}^{-}}$, and $\mathrm{Zn}^{\hat{2}^{-}}$. all four hydrosyethyl groups of $S$-THP or one anide and three hydrosyethyl groups of ATHC cannot coordinate to the metal ion if the metal ion coordinates to the nitrogens of the cyclen ring. In contrast. larger metal ions may form complexes where all oxygen and nitrogen donor atoms are coordinated such as the $\mathrm{Pb}^{2-}$ complex. Therefore, the relatively large $\mathrm{Eu}^{3-}$ and $\mathrm{La}^{3+}$ ions also form $\mathrm{S}$-THP and ATHC complexes with all nitrogens and hydroxyethyl groups coordinated in a manner reminiscent of lanthanide DOTA complexes.

Generally as one progresses from $\mathrm{La}^{3+}$ to $\mathrm{Eu}^{3-}$. the Lewis acidity of the lanthanide ion increases. ${ }^{201}$ Therefore, the decrease in ionic radius from $\mathrm{La}^{3-}$ to $\mathrm{Eu}^{3-}$ may modify the Lewis acidity and the resultant $\mathrm{p} K_{\mathrm{a}}$ values of bound water molecules as well as the coordination number of the lanthanide ion. ${ }^{\hat{1}}$ Changes in coordination and variation in the Lewis acidity of the lanthanide(III) (as measured by the $\mathrm{p} K_{a}$ of lanthanide water or lanthanide-bound hydrosyalhyl) are important properties to consider in choosing a trivalent lanthanide ion as a catalyst. Alcohol groups bound to Lewis acidic metal ions may be readily deprotonated. Such metal ion bound alkoxide ligands have previously been shown to act as nucleophiles in displacement reactions of phosphate diesters $^{18 a, 22}$ and nucleotide triphosphate. ${ }^{23}$

The $\mathrm{p} K_{\text {a }}$ value as determined by potentiemetric titration is 8.1 for the $\mathrm{La}(\mathrm{S}-\mathrm{THP})^{3-}$ complex. ${ }^{\text {18d }}$ Although the $\mathrm{p} K_{\mathrm{a}}$ value for $\mathrm{Eu}(\mathrm{ATHC})^{3+}$ is not known, the $\mathrm{p} K_{\mathrm{a}}$ values for $\mathrm{Eu}(\mathrm{ABHC})^{3-}$, $\mathrm{Eu}(\mathrm{THED})^{3+}$ and $\mathrm{Eu}(\mathrm{CNPHC})^{3-}$ are estimated to be 8.1. 7.5. and 7.5 suggesting that the bis(anide) complex is a poorer Lewis acid. ${ }^{11}$ Therefore, the $\mathrm{p} K_{\mathrm{a}}$ for the $\mathrm{Eu}(\mathrm{ATHC})^{3-}$ is expected to be smaller than the $\mathrm{p} K_{\mathrm{a}}$ of $\mathrm{La}(\mathrm{S}-\mathrm{THP})^{3+}$ complex. From comparison of $\mathrm{p} K_{\mathrm{a}}$ values. the $\mathrm{Eu}(\mathrm{ATHC})^{\hat{3}-}$ complex is the better Lewis acid than the La(S-THP) ${ }^{3-}$. One night have anticipated that the $\operatorname{Eu}(\mathrm{ATHC})^{3-}$ complex. as the better Lewis acid. would be the better promoter. However in the our results. increasing Lewis acidity of the lanthanide(III) (as indicated by $\mathrm{p} K_{\mathrm{a}}$ ) does not correlate to increasing effciency of the complex in promoting for the RNA cleavage. These results in reactivity are attributed in parts the larger number of coordination sites of $\mathrm{La}(\mathrm{S}-\mathrm{THP})^{3-}$ compared to the $\mathrm{Eu}(\mathrm{ATHC})^{3-}$ complex. Because of the larger size of the lanthium(III) ion. it likely that the coordination number in the macrocyclic complex is greater than that for the analogous europium(III) complex. The large number of coordination sites of the lanthanide(III) ions makes it possible to design complexes that do not readily dissociate in water yet retain open coordination sites for catalysis. This difference maỵ be important for cataly sis and may contribute to the larger $k_{c}$ obserbed for the lanthanium(III) complex.

Acknowledgment. This work was supported by Pukyong Research Abroad Fund in 2001. The author thanks Prof. J. P. Richard, Janet R. Morrow. and Dr. Ann Marie at Department of Chemistry, State University of New York. Buffalo. U.S. for valuable discussions and also for help in kinectic measuments throughout the course of this research

\section{References}

1. Iranzo. O ; Kovalevsky: A. Y; Morrow. J. R.: Richard. J. P. J. Am Chem. Soc. 2003, 125. 1988-1993.

2. Albedyhl. S.: Schneieders. D.: Tanso. A.: Gajda. T.: Kerbs. B. Ew: J. Whorg Chem 2002. 14001-1409.

3. Blasko. A.: Bruice. T. C. Ace. (hem. Res. 1999. 32. 475-484

4. Trawick. B. N.: Daniher, A. T.: Bashkin, J. K. Chem. Ren 1998. $19.939-960$

5. Cowan, A. J. Cwr Opin. Chem Biol 2001. 5.634-642.

6. Zhou. D. M.: Taira. K. Chem. Rev 1998. 98. 991-1026.

7. Perreault. D. M.: Anslyin. E. V. Angew, Chent. Int. Ed. Engl. 1997. $36.432-450$

8. Smith. P. H.; Raymond. K. N. horg Chem. 1985, 24.3469-3477.

9. Hancock. R. D.; Shaikjee. M. S.: Dobson. S. M.; Boeyens. J. C. A Inorg. Chim. Acta 1988, 154. 229-238.

10. Chappel. L. L.: Voss. D. A... Ir.: Horrocks. Dew.. Jr.: Morrow. T. R. lnorg. Chem. 1998. 37.3989-3998.

11. Chinl. K. O. A.: Morrow. T. R.: Lake. C. H.: Churchill. M. R. Inorg. Chem. 1994. 33.656-654.

12. Williams. N. H.: Takasaki, B.; Wall. M.: Chin, J. Acc. Chem Res. 1999. 32, $485-493$.

13. Oivanen. M.: Kuusela. S.: L nnberg. H. Chem Rev 1998. $98.961-$ 990 .

14. (a) Wang. X: .Tin. T:: Comblint. V:: Lopez-Mut. A.: Merciny. E.: Desreux. J. F. Inorg Chent 1992, 31. 1(195-1099. (b) Clarke, E. T.: Martell. A. E. horg Chim. Acta 1991. 190. 37-46. (c) Cacheris, W. P. Nickle. S. K.: Sherry. A. D. Inorg. Chem 1987. 26. 958-960. (d) Chang. C. A. Ew. J. Solid State Chem. 1991. 28 237-241

15. McMurray. T. J.: Brechbiel. M.: Kumar. K.: Gan1sow. O. A. Biocontugate Chem. 1992, 3, 108-117.

16. Kaden. T. A. Top. Cum: Chem. 1984. 121, 157

17. Morrow: J. R.: Chin, K. A. Jhorg. Chem. 1993. 32, 3357-3361

18. (a) Morrow: J. R.: Aures. K.: Epstein. D. J. Chem. Soc. Chem. Conmum. 1995. 2431. (b) Kimura. E.: Kodama. Y: Koike. T.: Shiro. M. J. Ant Chent Soc. 1995. 117. 8304. (c) Amin. S. A Morrow: J. R.: Lake, C. H. Churchill, M. R. Angew: Chem., Int Ed. Engl. 1994, 33. 773-775. (d) Chin, K. O. A.; Morrow. J. R Inorg. Chem. 1994. 33. 5036-5041.

19. Amin. S. A.: Voss. D. A.. Jr:: Horrochs. W. D.. Jr:: Lake. C. H.: Churchill. M. R.: Morrow. J. R. Inot Chem. 1995. 34. 3294.

20. Choppitr. G. R. In Lanthanide Probes in Life. Chemical and Earth Sciences. Theory and Practice: Bunzil, J, C. G.: Choppin, G. R. Eds:- Elsevier: New York, 1989.

21. Burgress, J. Metals Ions in Solutions, Wiely and Sons: New York. 1978.

22. Morrow. J. R.: Chit1. K. O. A.: Aures. K. Genetic Response to Metals: Sarker. B.. Ed.: Marcel Dekker: New York. 1995: pp 173184.

23. Sigman. D. S.; Wahl. G. M.; Creighton, D. Biochemistry 1972, 11 . 2236-2242. 